\title{
What is optimal in patients with myasthenic crisis: Invasive or non-invasive ventilation?
}

\author{
Hemant Bhagat, Vinod K. Grover, Kiran Jangra
}

\begin{abstract}
Myasthenia gravis is an immune disorder involving the neuromuscular junction. The consequent weakness of respiratory muscles leads to variable disorders of ventilation in patients with myasthenia gravis. This article reviews the options of invasive and non-invasive ventilation in patients with advanced form of the disease.
\end{abstract}

Key words: Invasive ventilation, myasthenia gravis, non-invasive ventilation

\section{INTRODUCTION}

Myasthenia gravis (MG) is an immunological neuromuscular disorder, characterized by fluctuating weakness and fatigability of skeletal muscles. ${ }^{[1]}$ There is an antibody-mediated autoimmune attack at the post-synaptic membrane of the neuromuscular junction leading to (a) reduction of acetylcholine receptors and (b) flattening of post-synaptic clefts. There is also a reduction in the amount of acetylcholine release with repeated activity (presynaptic rundown). These result in decreased efficiency of neuromuscular transmission with consequent weakness of muscle contraction. ${ }^{[1]}$

The prevalence of MG is $0.5-12.5$ per 10,000 population and incidence is 0.4 per 10,000 with a female preponderance. ${ }^{[2-4]}$ The myasthenic weakness increases with repeated use (fatigue) and improves with rest or sleep. Exacerbations and remissions may occur, though remissions are rarely complete or permanent. ${ }^{[1]}$ The morbidity and mortality is usually high in critically

\begin{tabular}{|l|l|}
\hline \multicolumn{2}{|c|}{ Access this article online } \\
\hline Quick Response Code: & Website: \\
\hline & www.jnaccjournal.org \\
\cline { 2 - 2 } & \\
\hline & \\
\hline
\end{tabular}

ill patients. The course of the disease is variable and mortality in early 1960s was as high as $40 \% .{ }^{[5]}$ Over the subsequent decades, there was improvement in specialized neurological intensive care unit (ICU) and the mortality reduced to $4-6 \%$. ${ }^{[6,7]}$

The features that best describe the myasthenia gravis include involvement of ocular and proximal muscles, usually asymmetric, no loss of sensation/neurological function/deep tendon reflexes. The diagnosis is confirmed by clinical response to cholinergic drugs (edrophonium or neostigmine test), electrodiagnostic studies and the presence of serum antibodies against acetylcholine receptors. ${ }^{[1]}$ The severity of clinical illness is best described by a modified Osserman classification [Table 1]. . $^{[8,9]}$ The pathophysiological changes following muscle

\begin{tabular}{ll} 
Table 1: Modified Osserman classification \\
\hline Class I & $\begin{array}{l}\text { Patients with ocular involvement alone } \\
\text { Class II }\end{array}$ \\
$\begin{array}{l}\text { Mild muscular weakness, not incapacitat- } \\
\text { ing }\end{array}$ \\
$\begin{array}{l}\text { Class III } \\
\text { poderate muscular weakness, not inca- } \\
\text { respiratory muscle weakness }\end{array}$ \\
Class IV & $\begin{array}{l}\text { Incapacitating weakness of any muscle sys- } \\
\text { tem, including oropharyngeal and respira- } \\
\text { tory muscle weakness }\end{array}$ \\
& $\begin{array}{l}\text { Life-threatening respiratory insufficiency } \\
\text { requiring ventilatory assistance (crisis) }\end{array}$ \\
\hline
\end{tabular}

Department of Anaesthesia and Intensive Care, Postgraduate Institute of Medical Education and Research, Chandigarh, India

Address for correspondence:

Dr. Hemant Bhagat, Department of Anaesthesia and Intensive Care, Postgraduate Institute of Medical Education and Research,

Chandigarh - 160 012, India. E-mail: drhemantbhagat@rediffmail.com 
weakness and the consequent clinical effects have been schematically presented in Figure 1. ${ }^{[10]}$

A critical care specialist may be expected to treat severely ill myasthenic patients in class 4 or 5 [Table 1]. These groups of patients are best managed in a specialized neurointensive care unit (NICU). Evaluation of critically ill myasthenic patients is very important to differentiate between the ones which have incapacitating oropharyngeal and respiratory muscle weakness (MG class IV, impending crisis) and the ones that are in respiratory failure (MG Class V, myasthenic crisis). The clinical signs and symptoms between the two classes are overlapping and probably the most important objective criteria to differentiate between Class IV and Class V MG would be (a) vital capacity (VC) and (b) arterial blood gas analysis. ${ }^{[11]}$

The simplest and the most reliable way to determine impending respiratory failure is by frequent use of bed side measurements of VC by handheld spirometer. ${ }^{[11]}$ A normal VC is approximately $55-65 \mathrm{ml} / \mathrm{kg}$ depending on age, body size and pre-existing respiratory disease. A reduction to $30 \mathrm{ml} / \mathrm{kg}$ is associated with poor cough and accumulation of oropharyngeal secretions. At the level of $25 \mathrm{ml} / \mathrm{kg}$ sigh mechanism are impaired and atelectasis develops which may result in mild hypoxaemia. If VC falls below $15 \mathrm{ml} / \mathrm{kg}$, respiratory failure ensues for which elective intubation is usually necessary to support ventilation so as to allow $\mathrm{O}_{2}$ exchange and prevent

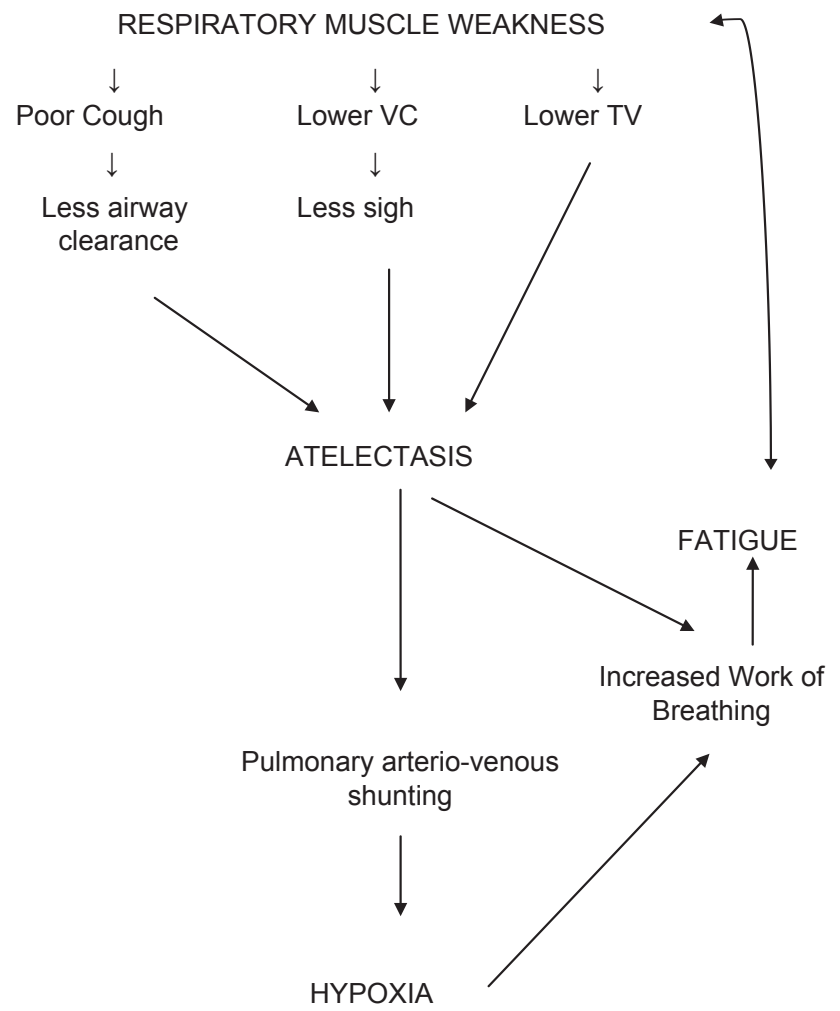

Figure 1: Pathophysiological effects of respiratory muscle weakness muscle fatigue. Arterial blood gas analysis is another important parameter to demonstrate respiratory failure. $\mathrm{PaO}_{2}$ less than $60 \mathrm{mmHg}$ or $\mathrm{PaCO}_{2}$ more than $50 \mathrm{mmHg}$ unequivocally diagnoses respiratory failure. ${ }^{[11]}$

The prognosis of MG has drastically improved as a result of advances in treatment modalities. Virtually, all myasthenic patients can be returned to productive lives with rational therapy, which includes judicious use of anticholine-esterase medications, immunosuppressive agents, thymectomy, plasmapheresis, intravenous immunoglobulins (IVIg) and advanced respiratory care. ${ }^{[1]]}$

There are two important issues in the management of critically ill myasthenic patients. The first is the need for airway protection and second is the need for mechanical ventilation. The literature clearly supports the conventional technique of intubation and mechanical ventilation to overcome these issues. The use of non-invasive ventilation is in a stage of evolution as far as respiratory management is concerned in myasthenic patients. Various aspects of invasive and non-invasive ventilation are discussed below.

\section{INVASIVE VENTILATION}

The use of ventilatory support in a patient via a definitive airway/invasive conduit is referred to as invasive ventilation. The invasive ventilation can be used via following airways ${ }^{[11,12]}$

1. Endotracheal tube

2. Tracheostomy tube

3. Mini-tracheostomy tube.

Advantages and disadvantages of invasive ventilation are tabulated in Tables 2 and 3. ${ }^{[13]}$

\section{Table 2: Advantages of invasive ventilation}

Early ventilation support is an option (in patients with class IV MG)

Intermittent ventilation is possible

Ventilation outside ICU is possible

Patients can eat/drink

Communication is possible

Patient can cooperate for physiotherapy

Avoids intubation

Reduces ICU/hospital stay

$\mathrm{ICU}=$ intensive care unit, $\mathrm{MG}=$ myasthenia gravis

\section{Table 3: Disadvantages of invasive ventilation}

Complications related to process of intubation

Complications due to ventilation

Loss of airway defense mechanism

Complications related to removal of endotracheal/ tracheostomy tube 
Endotracheal intubation carries well-known risks of complications. These fall into three main categories: complications directly related to the process of intubation and mechanical ventilation, those caused by the loss of airway defense mechanisms, and those that occur after removal of the endotracheal tube.

The first category includes aspiration of gastric contents, trauma to the teeth, hypopharynx, esophagus, larynx, and trachea, arrhythmias, hypotension, and barotrauma that may occur during placement of a translaryngeal tube. With tracheostomy placement, risks include hemorrhage, stomal infection, intubation of a false lumen, mediastinitis, and acute injury to the trachea and surrounding structures, including the esophagus and blood vessels.

In the second and third category, endotracheal tube provides a direct conduit to the lower airways for microorganisms and other foreign materials, permitting chronic bacterial colonization, inflammation, and impairment of airway ciliary function.

The last category includes hoarseness, sore throat, cough, sputum production, and hemoptysis. Upper airway obstruction caused by vocal cord dysfunction or laryngeal swelling, and tracheal stenosis may follow extubation.

\section{Evidence for use}

The conventional and popular mode of ventilation in myasthenic patients has been ventilator support via an endotracheal tube, tracheostomy and minitracheostomy. Tracheostomy is considered if patients requires airway protection/mechanical ventilation for more than 2 weeks. ${ }^{[1]}$ The evidence for use of invasive ventilation is strong and has been recommended in most of the series published so far. ${ }^{[5,6,8]}$ The mortality in the patients receiving invasive ventilation has been as low as $4-6 \%$.

In an unpublished data from a tertiary care neurological ICU in India, 59 patients with 74 episodes of myasthenic crisis were studied. ${ }^{[14]}$ The patients were intubated endotracheally and mechanically ventilated for median duration of 11 days. In $22.9 \%$ of episodes of crisis, tracheostomy was required. The outcome in terms of mortality $(6.7 \%)$ was comparable to most of the centers worldwide..$^{[7,15]}$

In another Indian study, where 23 episodes of myasthenia gravis were studied the median duration of crisis episode was 11 days. These patients were intubated and mechanically ventilated. Two (8\%) of the 23 episodes were fatal, one resulting from ventilator-associated pneumonia and another due to crisis itself. ${ }^{[16]}$

\section{NON-INVASIVE VENTILATION}

Non-invasive ventilation (NIV) refers to the delivery of mechanical ventilation using techniques that do not require a definitive airway. During non-invasive positive pressure ventilation, the gas is delivered to airway via a mask or a relevant interface. The open breathing circuit of NIV causes air leak around the mask, rendering its success to be critically dependent on ventilator system designed to deal effectively with air leaks and to optimize patients comfort and acceptance. ${ }^{[13]}$

The following interfaces are used for delivery of non-invasive ventilation ${ }^{[13,17]}$

1. Nasal masks

2. Oro-nasal masks

3. Mouth pieces

4. Helmet interface.

The ventilator modes that can be used are -

1. Continuous positive airway pressure (CPAP).

2. Pressure-limited ventilators

a. Pressure Support Ventilation (PSV)

b. Pressure-Controlled Ventilation (PCV)

c. Bi-level Positive Airway Pressure (BIPAP)

3. Volume-limited ventilators

4. Proportional assist ventilation-targets patient's efforts rather than pressure or volume.

Advantages and disadvantages of non-invasive ventilation are tabulated in Tables 4 and 5. ${ }^{[13,18]}$

\section{Table 4: Advantages of non-invasive ventilation}

Early ventilation support is an option (in patients with class IV MG)

Intermittent ventilation is possible

Ventilation outside ICU is possible

Patients can eat/drink

Communication is possible

Patient can cooperate for physiotherapy

Avoids intubation

Reduces ICU/hospital stay

$\mathrm{ICU}=$ intensive care unit, $\mathrm{MG}=$ myasthenia gravis

\section{Table 5: Disadvantages of non-invasive ventilation}

Airway is not protected, which is a major concern in myasthenic patients

No direct access to bronchial tree for suctioning of secretions (another concern in patients on optimal dose of anti-cholinesterases)

Efficacy for management of patient in myasthenia crisis is yet to be proven

Mask uncomfortable/claustrophobic (the patient may not be able to adjust the mask due to weakness and is totally dependent on others)

Facial pressure sores

Drug holiday may not be possible 


\section{Evidence for use}

There have been reports of the successful use of non-invasive ventilation in patients with MG. ${ }^{[17,18]}$ NIV can be especially useful in the management of myasthenic crisis. Although some previous studies concluded that early intubation for mechanical ventilation is an important step in the management of these patients. Other reports suggested that NIV could prevent intubation in myasthenia gravis patients with respiratory failure ${ }^{[18,19]}$ In a recent study reported by Seneviratne et al., NIV was the initial ventilator support in 24 episodes of myasthenic crisis and intubation was prevented in 14 episodes. ${ }^{[18]}$ In that study severe hypercapnia $\left(\mathrm{PaCO}_{2}>45 \mathrm{mmHg}\right)$ was a predictor of NIV failure. In another study NIV was recommended in myasthenia gravis if serum bicarbonate concentration was below $30 \mathrm{mmol} / \mathrm{L}^{[20]}$ and APACHE II Score was less than 6. In this study authors recommend serum bicarbonate is superior to $\mathrm{PaCO}_{2}$ in predicting NIV failure. None of the patients in this study had renal failure when admitted to ICU. The initial serum level of bicarbonate might be a better indicator of severity and chronicity of the respiratory acidosis and thereby the capacity of respiratory muscles. Patients in this study were more hypercapnic than the patients in the study conducted by Seneviratne et al.

Jenn-Yu Wu et al., have also analyzed NIV application after extubation. ${ }^{[20]}$ Intermittent NIV support was applied to $10(30.3 \%)$ out of 33 patients undergoing mechanical ventilation after extubation. Seven of them received NIV support $<6 \mathrm{~h} /$ day and were successfully prevented from reintubation. The other $3(30 \%)$ patients became NIV dependent immediately after extubation and were reintubated.

The experience of our institute is limited. However, the successful use of BIPAP in one patient who had hypercapnic respiratory failure has been reported. ${ }^{[21]}$ In an interesting case report, a 12-year-old girl suffering from seronegative MG was treated with helmet delivered NIV during recurrent myasthenic episodes. Never the less in one episode she had bronchopneumonia for which she had to be shifted to invasive approach.

In face of available evidence in support of non-invasive ventilation for exacerbation of MG, the findings of various studies and case reports probably generate a hypothesis that non-invasive ventilation may be a good option of ventilatory management in myasthenic patients with respiratory impairment and also may be useful in post-extubation period in patients who initially were intubated and mechanically ventilated.

\section{CONCLUSIONS}

1. The conventional endotracheal intubation and mechanical ventilation is still the gold standard for management of myasthenia crisis (MG Class $\mathrm{V}$ )

2. The use of non-invasive ventilation may be useful in managing patients with incapacitating respiratory muscle weakness (MG Class IV) and preventing the use of invasive ventilation

3. Initiation of BIPAP ventilation may be associated with shorter duration of ventilation as well as ICU and hospital stay

4. Arterial carbon-dioxide $\left(\mathrm{PaCO}_{2}\right)$ levels greater than $45 \mathrm{mmHg}$ on BIPAP, is one of the indicators for failure of BIPAP ventilation in myasthenia patients.

\section{REFERENCES}

1. Drachman DB. Myasthenia gravis. In: Isselbacher $\mathrm{KJ}$, Brauwald E, Wilson JD, Martin JB, Fauci AS, editors. Harrison's Principles of Internal Medicine, $13^{\text {th }}$ ed. New York: McGraw Hill; 1994. p. 2393-6.

2. Philips LH $2^{\text {nd }}$, Tomer JC, Anderson MS, Cox GM. The epidemiology of myasthenia gravis in central and western Virginia. Neurology 1992;42:1888-93.

3. Treves TA, Rocea WA, Meneghini F. Epidemiology of myasthenia gravis. In: Andreson DW, Schenberg DG, editors. Neuroepidemiology. A Tribute to Bruce Shoenberg. Boston: CRC Press; 1991. p. 297.

4. Ahuja GK, Mohandas S, Behari M. Myasthenia gravis: Experience with 70 patients. Neurol India 1983;31:15-23.

5. Cohen MS, Younger D. Aspects of the natural history of myasthenia crisis and death. Ann N Y Acad Sci 1981;377:670-7.

6. Gracey DR, Dievertie MB, Howard FM Jr. Mechanical ventilation for respiratory failure in myasthenia gravis. Two-year experience with 22 patients. Mayo Clin Proc 1983;58:597-602.

7. Thomas CE, Mayer SA, Gungor Y, Swarup R, Webster EA, Chang I, et al. Myasthenia crisis: Clinical features, mortality, complications and risk factors for prolonged intubation. Neurology 1997;48:1253-60.

8. Osserman KE, Geakins G. Studies in myasthenia gravis: Reduction in mortality rate after crises. JAMA 1963;183:97-101.

9. Osserman KE. Clinical aspects. In: Osserman KE, editor. Myasthenis gravis. New York: Grune and Stratton; 1958. p. 79-80.

10. Ropper AH, Shahani BT. Diagnosis and management of acute are flexic paralysis with special emphasis on Guillane-Barre syndrome. In: Ashbury AK, Gilliat RW, editors. Peripheral Nerve Disorders. London: Butterworth; 1984. p. 21-45.

11. Treatment of critically ill patients with myasthenia gravis. In: Ropper AH, Gress DR, Diringer MN, Green DM, Mayer SA, Bleck TP, editors. Neurological and Neurosurgical Intensive Care, $4^{\text {th }}$ ed. Philadelphia: Lippincott Williams and Wilkins; 2004. p. 299-311.

12. Nomori H, Ishihara T. Pressure controlled ventilation via a mini-tracheostomy tube for patients with neuromuscular disease. Neurology 2000;55:698-702.

13. Mehta S, Hill NS. Noninvasive ventilation. Am J Respir Crit Care Med 2001;163:540-77.

14. Sharma D, Bithal PK, Dash HH. Respiratory care of myasthenic crisis in neuro-intensive care unit: Evaluation of outcome and adverse events. DM (Neuroanaesthesiology) Research Project, 2006, AIIMS, New Delhi; 2006.

15. Varelas PN, Chua HC, Natterman J, Barmadia L, Zimmerman P, Yahia A, et al. Ventilatory care in myasthenia gravis crisis: 
Assessing the baseline adverse event rate. Crit Care Med 2002;30:2663-8.

16. Murthy JM, Meena AK, Chowdary GV, Narayanan JT. Myasthenia crises: Clinical features, complications and mortality. Neurol India 2005;53:37-40.

17. Piastra M, Conti G, Caresta E, Tempera A, Chiaretti A, Polidori $G$, et al. Non-invasive ventilation options in pediatric myasthenia gravis. Pediatr Anesth 2005;15:699-702.

18. Seneviratne J, Mandrekar J, Wijdicks EF, Rabinstein AA. Non-invasive ventilation in myasthenic crisis. Arch Neurol 2008;65:54-8.

19. Rabinstein A, Wijdicks EF. BiPAP in acute respiratory failure due to myasthenic crisis may prevent intubation. Neurology 2002;59:1647-9.
20. Wu JY, Kuo PH, Fan PC, Wu HD, Shih FY, Yang PC. The role of non-invasive ventilation and factors predicting extubation outcome in myasthenic crisis. Neurocrit Care 2009; 10:35-42.

21. Agarwal R, Reddy C, Gupta D. Non-invasive ventilation in acute neuromuscular respiratory failure due to myasthenic crisis: Case report and review of literature. Emerg Med J 2006;23:e6.

How to cite this article: Bhagat $\mathrm{H}$, Grover VK, Jangra $\mathrm{K}$. What is optimal in patients with myasthenic crisis: Invasive or non-invasive ventilation?. J Neuroanaesthesiol Crit Care 2014;1:116-20.

Source of Support: Nil, Conflict of Interest: None declared.

\section{“QUICK RESPONSE CODE” LINK FOR FULL TEXT ARTICLES}

The journal issue has a unique new feature for reaching to the journal's website without typing a single letter. Each article on its first page has a "Quick Response Code". Using any mobile or other hand-held device with camera and GPRS/other internet source, one can reach to the full text of that particular article on the journal's website. Start a QR-code reading software (see list of free applications from http://tinyurl.com/yzlh2tc) and point the camera to the QR-code printed in the journal. It will automatically take you to the HTML full text of that article. One can also use a desktop or laptop with web camera for similar functionality. See http://tinyurl.com/2bw7fn3 or http://tinyurl.com/3ysr3me for the free applications. 